\title{
Fault Detection and Classification on a Transmission Line using Wavelet Multi Resolution Analysis and Neural Network
}

\author{
Mamta Patel \\ Dept. of Elect. Engg. \\ Govt. Poly Durg, India
}

\author{
R. N. Patel, PhD \\ Dept. of Elect. Engg. \\ S.S.C.E.T, Durg, India
}

\begin{abstract}
Transmission and distribution lines are vital links between generating units and consumers. They are exposed to atmosphere, hence chances of occurrence of fault in transmission line is very high, which has to be immediately taken care of in order to minimize damage caused by it. In this paper discrete wavelet transform of voltage signals at the two ends of the transmission lines have been analyzed. Transient energies of detail information for two consecutive data windows at fault are used for analysis. Four layer feed forward back propagation neural networks are designed to classify and locate the fault at different single line to ground fault conditions.
\end{abstract}

\section{General Terms}

Fault classification and detection, wavelet multi resolution analysis, neural network.

\section{Keywords}

Wavelet, Discrete wavelet transform, Multi resolution analysis, Transient energy, Neurons, Feed forward back propagation neural network.

\section{INTRODUCTION}

Transmission lines constitute the major part of power system. Transmission and distribution lines are vital links between the generating unit and consumers to achieve the continuity of electric supply. To economically transfer large blocks of power between systems and from remote generating sites, High voltage (HV) and Extra high voltage (EHV) overhead transmission systems are being used. Transmission lines also form a link in interconnected system operation for bidirectional flow of power. Transmission lines run over hundreds of kilometers to supply electrical power to the consumers. They are exposed to atmosphere, hence chances of occurrence of fault in transmission line is very high which has to be immediately taken care of in order to minimize damage caused by it. It will also facilitate quicker repair, improve system availability and performance, reduce operating cost and save time and effort of maintenance crew searching in, sometimes in harsh environmental conditions. It has always been an interest for engineers to detect and locate the faults in the power system as early as possible. Fast clearing and restoration is very essential as it not only provides reliability but sometimes also stops propagation of disturbances which may lead to blackouts. Various fault detection and location methods have been proposed for this purpose, which can be categorized as below [1]
- Technique based on fundamental frequency currents and voltages, mainly on impedance measurement.

- Technique based on travelling wave phenomenon.

- Technique based on high frequency components of currents and voltages generated by faults.

- Knowledge based approaches.

Techniques based on high frequency components of currents and voltages generated by faults mainly comprise wavelet based protection system [2]-[6]. Wavelet transform in conjunction with AI/Fuzzy/expert system based technique have the advantage of fast response and increased accuracy as compared to conventional techniques [7]-[9]. Wavelet transform in conjunction with AI/Fuzzy/expert system based techniques have the advantage of fast response and increased accuracy as compared to conventional techniques [7]-[9]. Recently, a lot of research efforts have been focused on fault location techniques both in transmission and distribution network using knowledge based (artificial intelligence) methods, such as artificial neural networks, fuzzy set theory and expert systems[10]-[24].

This paper includes a new approach based on wavelet multiresolution analysis and feed forward back propagation neural network. When a fault occurs in transmission line, it initiates a transition condition. These signals have a finite life i.e. they decay to zero in a finite time. Transients produce overvoltage and over currents in the power system, which can damage it depending upon its severity; they also contain useful information which can be used for analyzing disturbances in transmission lines [10] [25]-[34]. The consequences of transients are presence of high frequency components in voltage and current fault signals. Various methods have been proposed to extract useful information from these high frequency components or harmonics. These methods are based on Fourier transform, wavelet transform, artificial neural network, fuzzy logic or combination of these techniques. Fourier transform and wavelet transform are the two major tools which are a great help in frequency domain analysis of any signal [35]. Fourier transform of a signal gives information about all the frequencies present in the signal but does not give any information about the time at which these frequencies were present. Wavelet transform is tool which helps the signal to analyze in time as well as frequency domain effectively. It provides non-uniform division of frequency domain i.e. it uses short window at high frequencies and long window at low frequencies. Using multiresolution analysis a particular band of frequencies present in the fault signal can be analyzed. 


\section{DISCRETE WAVELET TRANSFORM}

Transient voltages and currents during fault carry high frequency component or harmonics which carry important information regarding type and location of fault. Wavelets can be very effectively used in analyzing transient phenomenon of the fault signals. Multi-resolution analysis is one of the tools of Discrete wavelet transform, which decomposes the original signal to low frequency signal called approximations and high frequency signals called details. The important elements in analyzing transient signal using wavelet transform are to select mother wavelet and to decide the number of multiple decomposition steps. The number of decomposition steps is influenced from the sampling frequency of the original signals. In the first decomposition step the signal is decomposed into D1 component of high frequency band and A1 component of low frequency band. The frequency band of D1 component is $\left(f_{s} / 2-f_{s} / 4\right) \mathrm{Hz}$ and $\mathrm{A} 1$ component is $\left(f_{s} / 4-0\right), f_{s}$ being the sampling frequency. In the second decomposition step, A1 component extracted from the first decomposition step is again decomposed. Thus, D2 component of high frequency band and A2 component of low frequency band is achieved. The frequency band of $\mathrm{D} 2$ component is $\left(f_{s} / 4-f_{S} / 8\right) \mathrm{Hz}$ and the frequency band of $\mathrm{A} 2$ component is $\left(f_{s} / 8-0\right) \mathrm{Hz}$.

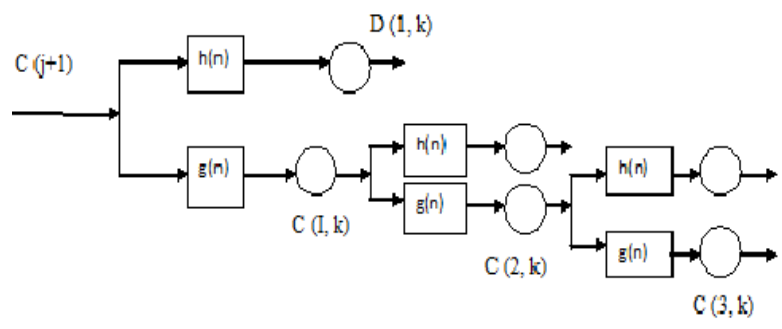

Fig. 1: Multiple level decomposition of the signal using DWT

The signal of the desired component can be extracted via repetitious decomposition. Number of decomposition steps should be decided by comparing the scale of sampling frequency with that of the frequency component of the desired signal. Fig. 1 shows the multi resolution steps of the signal $c$ $(j+1)$.

\section{NEURAL NETWORK}

A neural network is a parallel system, capable of resolving paradigms that linear computing cannot. They are used for applications where formal analysis is difficult or impossible such as pattern recognition and non linear system identification and control.

Neural networks are composed of simple elements which operate in parallel with interconnection between them. The weights of connection determine the network function. It is considered as the simplest kind of feed forward network. A neural network when created, has to be configured which is done using training function. The elements of the network are adjusted automatically to get a particular target output for specific input. A network can have several layers. Each layer has a weight matrix, a bias vector and an output vector. Each neuron in one layer has direct connections to the neurons of the subsequent layer. The second class of feed forward neural network distinguishes itself by the presence of one or more hidden layers, whose computation nodes are called hidden neurons or hidden units. By increasing the number of layers and neurons the network is enabled to extract higher order statistics which is advantageous when number of inputs is large and highly nonlinear. A neural network learns from its environment. In this process parameters of a neural network are adapted through a continuing process of simulation by the environment in which the network is embedded. A popular model for ANN is multilayered feed forward back propagation. The multi-layer perceptron has the ability of handling complex and non-linear input-output relationship with hidden layer. In this back propagation algorithm in the process of supervised learning, the errors are propagated backwards. The idea of back propagation algorithm is to reduce error until the ANN learns the training data. The training begins with random weights and the goal is to adjust them so that the error will be minimal. In this work multilayer feed forward network has been chosen to process the prepared input data which were obtained from wavelet transform.

\section{EXTRACTION OF TRANSIENT ENERGY USING WAVELET TRANSFORM}

The simulated transient signals are obtained from high voltage transmission line Simulink model and are analyzed for various conditions of single line to ground fault. Using wavelet multi resolution analysis the detail components at level 1 and level 5 have been taken into account. A moving data window of one cycle width has been taken for analysis.

The fault signals are discretized for analysis and so they are called discrete time signals. The sampling frequency is 320 $\mathrm{kHz}$, thus one data window contains 6400 samples. The total energy of a discrete time signal in one data window can be obtained with the help of following relation:

$$
\boldsymbol{E}=\sum_{n 1}^{n 1+6400}|x(n)|^{2}
$$

\section{PROPOSED METHOD}

A $220 \mathrm{kV}$ power system is simulated using MATLAB®/Simulink, SimPowerSystem toolbox, wavelet toolbox and neural network toolbox for different fault conditions on the line. The single-line diagram of the system under study is shown in Fig. 2.

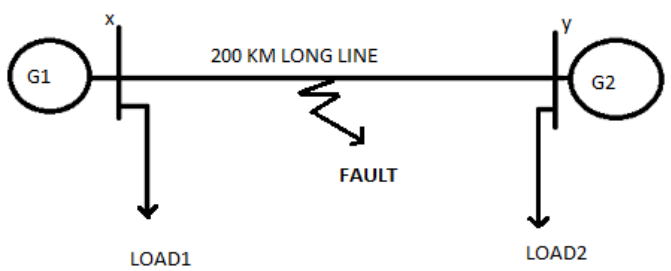

G1:GENERATOR1

G2:GENERATOR2

Fig. 2: Single line diagram of transmission line

The details of power system model are as given in Table- 1 . The line voltage signals from both the ends of are used for fault analysis on the transmission line. The signals are sampled at a frequency of $320 \mathrm{KHz}$, which gives 6400 samples per cycle. Daubechies 'db5' wavelet is employed since it has been demonstrated to perform well. The details of the Wavelet and associated parameters are given in Table -2 . Using multi resolution wavelet analysis of all the six voltage signals their detail D1 and D5 components are extracted. The fifth level 
detail D5 contains harmonics ranging from $5 \mathrm{kHz}-10 \mathrm{kHz}$ and the first level detail D1 contains harmonics ranging from 80 $\mathrm{kHz}-160 \mathrm{kHz}$.

It has been observed that variations within the detail information of the voltage signal contains useful fault signature. All the single line to ground faults were studied with different fault conditions. Fault is simulated to appear in second cycle. The transient energy is calculated for first three data window and were used for further analysis. Details of fault analysis are given in the next section.

Table - 1: Parameters of the Power System

\begin{tabular}{|l|l|}
\hline Generator 1 & $220 \mathrm{kV}, \mathrm{Y}-\mathrm{g}, \mathrm{X} / \mathrm{R}=10$, Phase Angle $=\mathrm{O}^{0}$ \\
\hline Generator 2 & $\begin{array}{l}220 \mathrm{kV}, \mathrm{Y}-\mathrm{g}, \mathrm{X} / \mathrm{R}=10, \text { Phase angle at } \\
\mathrm{A}=75^{\circ}\end{array}$ \\
\hline Load1 & $20 \mathrm{~kW}$ Active, $900 \mathrm{~W}$ Reactive \\
\hline $\begin{array}{l}\text { Load2 } \\
\text { line } \\
\text { (Distributed) }\end{array}$ & $\begin{array}{l}\text { Length }=200 \mathrm{~km} \\
\mathrm{R}=0.01273 \Omega / \mathrm{km}, \mathrm{R}_{0}=0.3864 \Omega / \mathrm{km} \\
\end{array}$ \\
& $\begin{array}{l}\mathrm{C}=0.9337 \mathrm{e}-3 \mathrm{H} / \mathrm{M}, \mathrm{L}_{0}=4.1264 \mathrm{e}-3 \mathrm{H} / \mathrm{km} \\
\end{array}$ \\
\hline
\end{tabular}

Table - 2: Details of Wavelet and associated paremeters

\begin{tabular}{|l|l|}
\hline Mother wavelet & Doubechies, db5 \\
\hline Sampling frequency & $320 \mathrm{kHz}$ \\
\hline Information analyzed & $\begin{array}{l}\text { Detail at level 5 and level 1, } \\
\text { D5, D1 }\end{array}$ \\
\hline Frequency band of D5 & $5 \mathrm{kHz}-10 \mathrm{kHz}$ \\
\hline Frequency band of D1 & $160 \mathrm{kHz}-80 \mathrm{kHz}$ \\
\hline $\begin{array}{l}\text { Number of samples per } \\
\text { cycle }\end{array}$ & 6400 \\
\hline $\begin{array}{l}\text { Occurrence of fault } \\
\text { Data window length } \\
\text { analyzed }\end{array}$ & One cycle/ 20msec \\
\hline
\end{tabular}

\section{FAULT ANALYSIS}

The six voltage signals for different fault conditions for single line to ground earth faults were taken into account. As stated earlier energies of D1 and D5 for data window for each signal was calculated and zero sequence current is also discretized and measured as fault voltages. Value of energy for zero sequence current for the same data window is also calculated. Fig. 3 shows the three phase voltage waveform at terminal $X$ when a single line to ground fault occurs at $50 \mathrm{kms}$ from it. Fig. 4 depicts detail D1 and Fig. 5 depicts detail D5 of the fault signal Vxa. It can be observed from these figures that maxima of D1 is about $2.5 \mathrm{e} 4$ volts and that of D5 is $4.5 \mathrm{e} 4$ volts. Hence, it can be concluded that harmonics in D5 contain higher energy than that of D1 during disturbance in line.

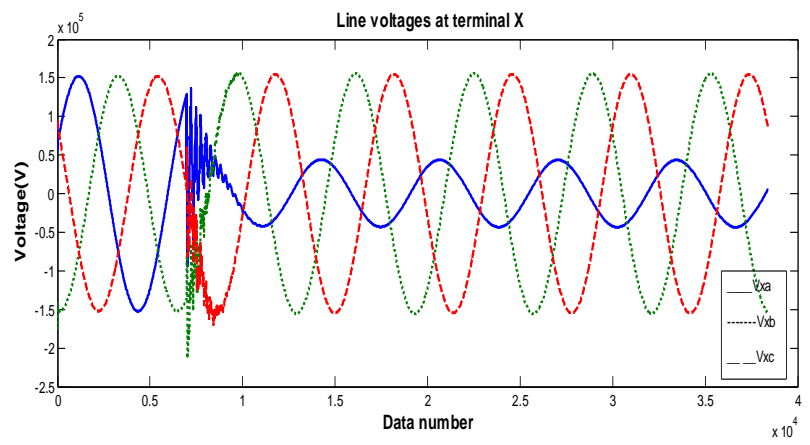

Fig. 3: LGA fault at $50 \mathrm{~km}$ from terminal $X$

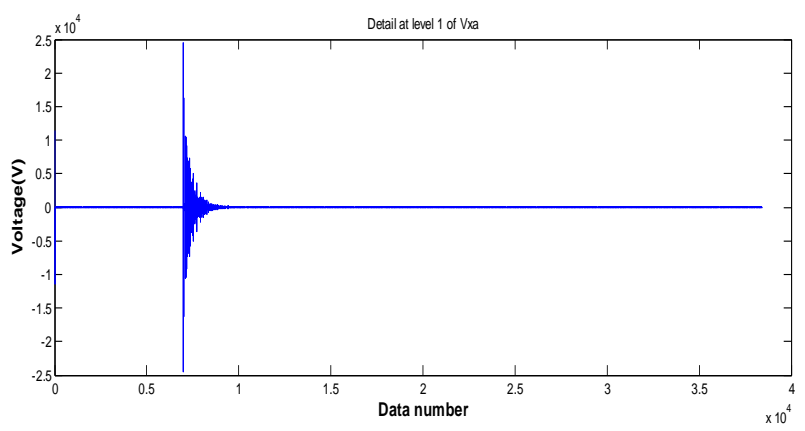

Fig. 4: Detail at level 1 of fault signal Vxa

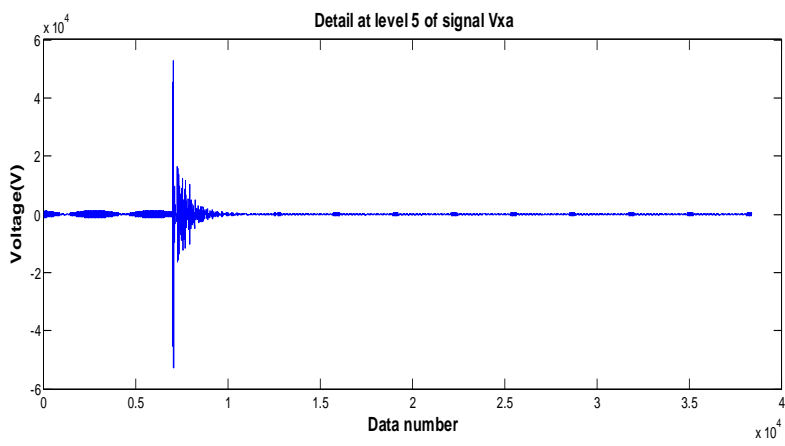

Fig. 5: Detail at level 5 of fault signal Vxa

Fig. 6 shows the proposed methodology for classifying and detecting the fault. As stated second data window contains the fault instant. A program was developed in MATLAB to find the energy in the first three data windows individually. The actual values can be obtained by multiplying the graph value with 6400 . Following points were concluded by studying the data. 
1. It is observed that transient energy increases sharply in the second data window in all the lines i.e. healthy as well as faulty.

2. In most of the cases it is highest in the faulted line as compared to healthy lines.

3. Value of energy in second data window is very much nonlinear with location of fault and type of fault.

4. Even healthy lines go through disturbances and contain harmonics and hence transient energy at the instant of fault.

5. Detail D5 contains higher energy than that of detail D1.

The results show that the decaying of the transient energy can be taken as a parameter for locating as well as classifying the fault. It gives a very convincing result for locating and classifying fault.

\subsection{Classification of faults}

All the three single line to ground faults were simulated for different fault conditions and results were analyzed. For classifying single line to ground fault, a fourteen input and four output feed forward back propagation neural network with four layers was designed. Energy of two consecutive windows of all six voltage signals $5^{\text {th }}$ level detail along with energy of zero sequence currents at the two terminals for the same data window was taken as input. Initial three outputs show the status of three lines; output is high (1) if a fault exists and low (0) if there is no fault. The fourth output is to distinguish earth fault and line fault; a high (1) indicates the earth fault and low (0) indicates the line fault. Table 3 gives a summary of observations for different fault conditions with faults at different phases, at different locations and at different fault inception angles.

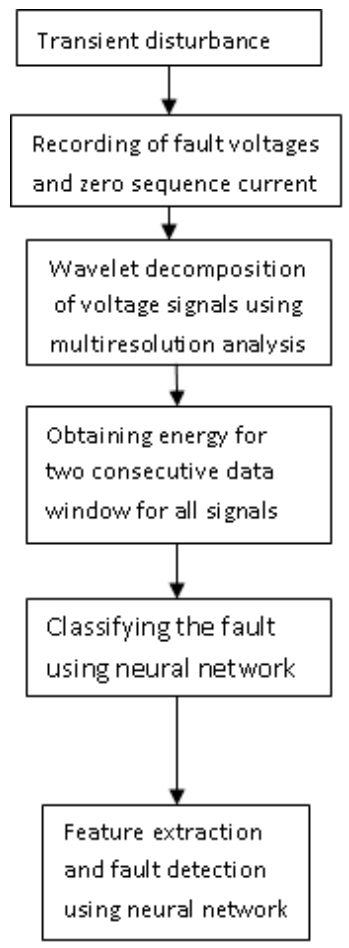

Fig. 6: Procedure for fault analysis

The results obtained from the proposed ANN perfectly indicate the specific fault conditions (a value above 0.9 can be taken as high or 1 , and a value below 0.1 can be treated as low or 0 ).
Table -3: Fault Classification using Wavelet and ANN

\begin{tabular}{|c|c|c|c|c|c|c|}
\hline $\begin{array}{l}\text { Typ } \\
\text { e of } \\
\text { faul } \\
t\end{array}$ & $\begin{array}{l}\text { Locati } \\
\text { on of } \\
\text { fault }\end{array}$ & $\begin{array}{l}\text { Fault } \\
\text { incep } \\
\text { tion } \\
\text { angle }\end{array}$ & $\mathbf{A}$ & B & $\mathrm{C}$ & $\mathbf{N}$ \\
\hline \multirow[t]{5}{*}{$\begin{array}{l}\text { LG } \\
A\end{array}$} & 55 & 90 & 0.9991 & $\begin{array}{l}7.014 \\
\text { e-5 }\end{array}$ & $\begin{array}{l}5.407 \\
5 e-4\end{array}$ & 1 \\
\hline & 78 & 60 & 0.9983 & $\begin{array}{l}6.687 \\
\text { e-5 }\end{array}$ & $\begin{array}{l}0.001 \\
6\end{array}$ & 1 \\
\hline & 92 & 45 & 0.9962 & $\begin{array}{l}1.663 \\
\text { e-4 }\end{array}$ & $\begin{array}{l}1.900 \\
2 \mathrm{e}-4\end{array}$ & 1 \\
\hline & 134 & 30 & 0.9992 & $\begin{array}{l}7.241 \\
e-5\end{array}$ & $\begin{array}{l}4.173 \\
7 e-4\end{array}$ & 1 \\
\hline & 167 & 0 & 0.9842 & $\begin{array}{l}6.036 \\
\text { e-5 }\end{array}$ & 0.045 & 1 \\
\hline \multirow[t]{5}{*}{$\begin{array}{l}\text { LG } \\
B\end{array}$} & 28 & 90 & $\begin{array}{l}5.2716 \\
\text { e-5 }\end{array}$ & 0.997 & $\begin{array}{l}3.202 \\
\text { e- } 4\end{array}$ & 1 \\
\hline & 87 & 60 & $\begin{array}{l}5.3967 \\
\text { e-5 }\end{array}$ & 0.998 & $\begin{array}{l}3.011 \\
1 \mathrm{e}-4\end{array}$ & 1 \\
\hline & 103 & 45 & $\begin{array}{l}5.4308 \\
\text { e-5 }\end{array}$ & 0.998 & $\begin{array}{l}2.971 \\
\text { e-4 }\end{array}$ & 1 \\
\hline & 145 & 30 & $\begin{array}{l}8.2748 \\
\text { e-5 }\end{array}$ & 0.994 & $\begin{array}{l}2.983 \\
1 \mathrm{e}-4\end{array}$ & 1 \\
\hline & 176 & 0 & 0.0021 & 0.999 & $\begin{array}{l}5.982 \\
\text { e-4 }\end{array}$ & 1 \\
\hline \multirow[t]{5}{*}{$\begin{array}{l}\text { LG } \\
\mathrm{C}\end{array}$} & 15 & 90 & $\begin{array}{l}5.8887 \\
\text { e-4 }\end{array}$ & $\begin{array}{l}1.917 \\
\text { e-5 }\end{array}$ & 0.999 & 1 \\
\hline & 38 & 60 & $\begin{array}{l}5.572 \\
\text { e-4 }\end{array}$ & $\begin{array}{l}1.90 \\
\text { e-5 }\end{array}$ & 0.999 & 1 \\
\hline & 116 & 45 & $\begin{array}{l}5.5735 \\
\mathrm{e}-4\end{array}$ & $\begin{array}{l}1.905 \\
\text { e-5 }\end{array}$ & 0.999 & 1 \\
\hline & 182 & 30 & $\begin{array}{l}5.5742 \\
\mathrm{e}-4\end{array}$ & $\begin{array}{l}1.906 \\
\text { e-5 }\end{array}$ & 0.999 & 1 \\
\hline & 97 & 0 & $\begin{array}{l}5.5743 \\
\text { e-4 }\end{array}$ & $\begin{array}{l}1.906 \mathrm{e}- \\
5 \mathrm{e}-5\end{array}$ & 0.999 & 1 \\
\hline
\end{tabular}




\subsection{Detection of Faults}

All types of single line to ground faults were simulated and observations were taken. Here single line to ground fault in phase A has been discussed below in detail.

The information of the transient energy in faulted window, which contains the energy of the frequency band $5-10 \mathrm{kHz}$ (level 5) and frequency band $80-160 \mathrm{kHz}$ (level 1) are shown in Fig. 7. It is observed that high frequency energy is less as compared to low frequency energy. But the energy is changing nonlinearly with location of fault.

Fig. 8 shows the decaying transient energy with location of fault, whcuh was observed for the energy in the third data window. Fig. 9 shows how the transient energies are different for healthy and faulted lines in third data window. It is evident from these results that the decaying transient energy in healthy and faulted lines can be distinguished clearly. Values were studied at both ends and for both levels (i.e. level-1 and level-5).

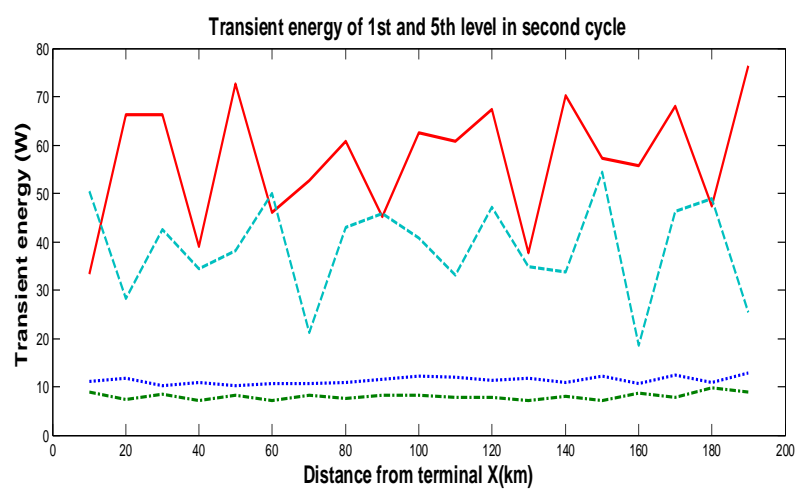

Fig. 7: Transient energy in second data window

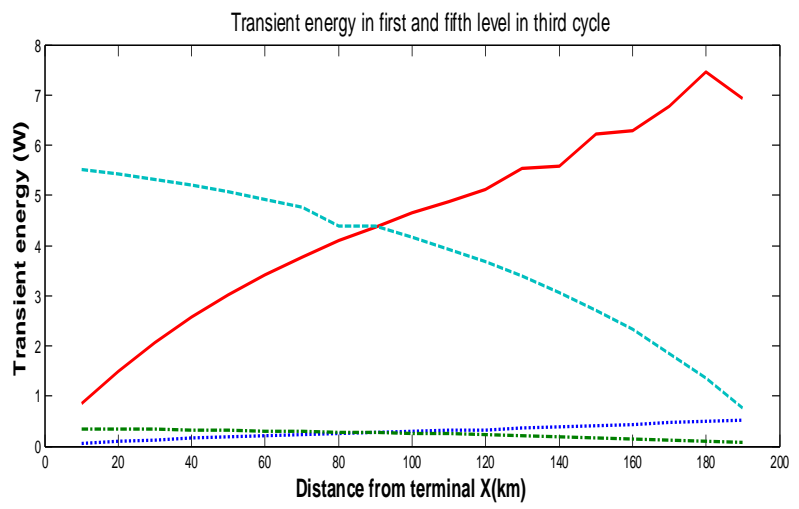

Fig. 8: Transient energy in third data window

Legends (Line styles) used are:

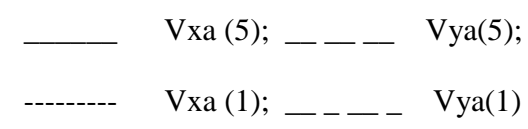

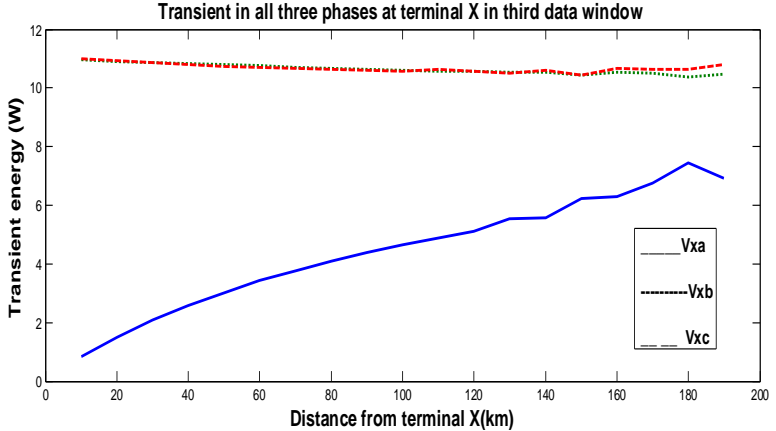

Fig. 9: Decaying transient energy of faulted and healthy lines

Table-4: Fault Distance Location using Wavelet and ANN

\begin{tabular}{|c|c|c|c|c|}
\hline $\begin{array}{l}\text { Type } \\
\text { of } \\
\text { fault }\end{array}$ & $\begin{array}{l}\text { Location } \\
\text { of fault }\end{array}$ & $\begin{array}{l}\text { Fault } \\
\text { inception } \\
\text { angle }\end{array}$ & $\begin{array}{l}\text { Wavelet } \\
\text { and ANN } \\
\text { based fault } \\
\text { locater } \\
\text { output }\end{array}$ & $\begin{array}{l}\% \\
\text { error }\end{array}$ \\
\hline \multirow[t]{5}{*}{ LGA } & 55 & 90 & 53.9622 & -1.88 \\
\hline & 78 & 60 & 77.2255 & -0.99 \\
\hline & 92 & 45 & 92.0286 & 0.09 \\
\hline & 134 & 30 & 139.2605 & 3.9 \\
\hline & 167 & 0 & 176.5844 & 5.74 \\
\hline \multirow[t]{5}{*}{ LGB } & 28 & 90 & 27.4472 & -1.97 \\
\hline & 87 & 60 & 90.3275 & 3.82 \\
\hline & 103 & 45 & 103.2484 & 0.241 \\
\hline & 145 & 30 & 148.303 & 2.27 \\
\hline & 176 & 0 & 189.379 & 7.6 \\
\hline \multirow[t]{5}{*}{ LGC } & 15 & 90 & 13.6723 & -8.85 \\
\hline & 38 & 60 & 36.9657 & -2.72 \\
\hline & 97 & 0 & 95.8447 & 1.19 \\
\hline & 116 & 45 & 113.323 & -2.3 \\
\hline & 182 & 30 & 179.2931 & -1.48 \\
\hline
\end{tabular}


In order to detect the location of fault a four level artificial neural network was designed. Decaying transient energy in first and fifth levels at both ends of the transmission line was taken as the input. Table- 4 shows few results for the proposed Wavelet and ANN based fault locater various fault locations and inception angles. It is observed that the predicted fault location by the trained ANN is very close to the actual fault location and the errors were below 5\% for most of the cases. In case of transmission lines, this error is quite reasonable as the distance between the two towers is quite large and it is good enough to know the location of fault between towers, which can then be easily corrected.

\section{CONCLUSIONS}

This paper presents the application of wavelet multi resolution analysis in combination with artificial neural network for accurate classification and location of single line to ground fault. The method uses energy of spectrum D1 and D5 for two consecutive data windows for classification and location of faults. Wavelet transform is used to get details D1 and D5 of the voltage signals. Capabilities of neural network in pattern classification were utilized to classify the faults. After successful classification, details of fault signals are used to locate the fault. Simulation studies were performed for different fault conditions with faults at different phases, at different locations and at different fault inception angles and performance of the proposed scheme was investigated. The classification of faults was exact and the location of the faults was identified with above $95 \%$ accuracy. This work deals with fault classification and detection for single line to ground faults, but the proposed algorithm and scheme can be extended to other faults also with same effectiveness.

\section{REFERENCES}

[1] Saha M.M., Zykowski R. J., Eugeniusz, 2010. Fault Location on power networks. Springer.

[2] Chen W., Malik O.P., Yin X., Chen D., Zhang Z., 2003. Study of wavelet based ultra high speed directional transmission line protection. IEEE Trans Power Delivery.

[3] Chanda D., Kishore N.K., Sinha A.K., 2003. A wavelet multiresolution analysis for location of faults on transmission lines. Electrical Power and Energy Systems.

[4] Hosung J., Young P., Moonseob H., Chanbmu L., Hyunjune p., Myongchul S., "Novel technique for fault location estimation on parallel transmission lines using wavelet", Electrical Power and Energy Systems; 29:7682, 2007.

[5] Fan C., Li K.K., Chan W. L., Weiyong Y, 2006.Study of protection scheme for transmission line based on wavelet transient energy. Electrical Power and Energy Systems.

[6] Bhowmik P. S.,Purkait, Bhattacharya P. K.,2009. A novel wavelet transform aided neural network based transmission line fault analysis method. Electrical Power and Energy Systems.

[7] Kim C.H., Kim H., Ko Y.H., Byun S.H., Aggrawal R.K., Johns A.T.,2002. A novel fault detection techique of high impedance arcing faults in transmission lines using the wavelet transform. IEEE Power Engineering Review.
[8] Misiti M. Misiti Y. Wavelet toolbox user's guide. Mathworks Ltd.

[9] Kale V.S., Bhide S.R., Bedekar P.P., Mohan G.V.K.,2008. Detection and classification of faults on parallel transmission lines using wavelet transform and neural network.

[10] Solanki M., Song Y.H.,2003. Transient protection of EHV transmission line using discrete wavelet analysis, Power Engineering Society General Meating, IEEE.

[11] Gafoor S.A., Ramana Rao P.V.,2006. Wavelet based fault detection, classification and location in transmission line., Power and Energy Conference, PECon '06, IEEE International.

[12] Valsan S.P., Swarup K.S.,2009. Wavelet transform based digital protection for transmission line. Electrical Power and Energy Systems.

[13] Nan Z, Kezunovic M.,2007. "Transmission line boundry protection using wavelet transform and neural network, IEEE Transaction on Power Delivery.

[14] Zhang D.J., Wu Q.H., Bo Z.Q., Caunce B.,2003. Transient positional protection of transmission lines using complex wavelet analysis. IEEE Transaction on Power Delivery.

[15] Ghosh S., 2008. Signals and Systems. Pearson Education.

[16] Abur A., Magnago F.H., 2000. Use of time delays between model components in wavelet based fault location. Electrical Power and Energy Systems.

[17] Chiradeja, Pathomthat, Pothisarn, Chaichan, 2009 Discrete wavelet transform and Fuzzy Logic algorithm for identification of faultntypes on transmission line. Advances in Power System Control, Operation and Management(APSCOM 2009).

[18] Jain A., Thoke A.S., Patel R.N., 2008.Fault classification of double circuit transmission line using artificial neural network. International Journal of Electrical Systems Science and Engineering 2008.

[19] Liang F., Jeyasurya B.,2004. Transmission line distance protection using wavelet transform algorithm, IEEE Trans power Delivery 2004.

[20] Megahed A.I., Moussa A.M., Bayoumy A.E., 2009. Usage of wavelet transform in the protection of wavelet transform in the protection of series compensated transmission lines, IEEE Transaction on Power Delivery 2009.

[21] Osman A.H., Malik O.P., 2004. Transmission line distance protection based on wavelet transform, IEEE Trans. power Delivery 2004.

[22] Phadke A.G., Thorp J.S., 1988. Computer relaying for power systems. Wiley and Sons, 1988.

[23] Reddy M.J., Mohanta D.K.,2007. A wavelet- fuzzy combined approach for classification and location of transmission line faults, Electrical Power and Energy Systems; 2007.

[24] Youssef O.A.S., 2004. Combined fuzzy logic waveletbased fault classification technique for power system relaying, IEEE Transaction on Power Delivery; 2004 
[25] Xia M.C., Zhuang Y., Huang, 2010. Wavelet analysis in transient based protection for power system high voltage transmission line. Proceedings of the 2010 International Conference on Wavelet Analysis and Pattern Recognition, Quingdao.

[26] Mahmood F, Prof. Qureshi S.A., Prof. Kamran M., 2008.Application of wavelet multi-resolution analysis \& perceptron neural networks for classification of transients on transmission line, 2008 Australian University Power Engineering Conference (AUPEC'08).

[27] Mingchao X., Yihuang H., 2008. Transient based protection using current transient", $2^{\text {nd }}$ IEEE International Conference on Power and Energy (PECon 08) 2008, Johor Baharu, Malasia.

[28] Jaipradidtham C., Pasomkusolsil S., 2008. Harmonic analysis of Electromagnetic Transients in $500 \mathrm{kv}$ single circuit transmission system using Discrete wavelet transform, Power System Technology and IEEE Power India Conference 2008 (POWERCON 2008).

[29] Kale V.S., Bhide S.R., Bedekar P.P., 2009. Faulted phase selection on double circuit transmission line using wavelet transform and neural network, Third International Conference on Power System, Kharagpur, India.
[30] Hatem A. Darwish, Abdel Maksoud I. Taalab, A.H. Osman, Neema M. Mansour and O. P. Malik, "Spectral Energy Differential Approach for Transmission Line Protection", Power system conference and exposition 2006 (PSCE 06) page 1931-1937.

[31] Costa F.B., Silva K.M., Souza B.A., Dantas K.M.C. and Brito N.S.D. 2006. A method for fault classification in Transmission Lines based on ANN and wavelet Coefficient Energy, International Joint Conference on Neural Networks vancouver, BC, Canada, , 2006.

[32] Othman M.F. and Amari H.A., 2008. Online fault detection for power system using wavelet and PNN, $2^{\text {nd }}$ IEEE International Conference on Power and Energy (PECon 08), Johor Baharu, Malasia.

[33] Patel M\& Patel R.N., 2011.Transient energy and its impact on Transmission line faults, World Acadamy of Science and Technology.

[34] Mingchao X., Yizhuang H., 2004. A novel unit transient based protection criterion for high- voltage power transmission line, IEEE Conference Publication (TENCON 2004).

[35] Abdollahi A., Seyedtabali S., 2010. Transmission line fault location estimation by Fourier \& Wavelet Transforms using ANN", The $4^{\text {th }}$ International Power Engineering and Optimization Conf. (PEOCO2010), Shah Alam, Selanger, Malasia. 